\title{
Key profibrotic and pro-inflammatory pathways in the pathogenesis of diabetic kidney disease
}

Received 22 December 2020

Accepted 31 January 2021

\author{
Devang M. Patel ${ }^{1}$, Yuxin Yang ${ }^{1,2}$, Kexin Shi ${ }^{1}$, Tieqiao Wu ${ }^{1}$, Mark E. Cooper ${ }^{1,3, *}$, Zhonglin Chai ${ }^{1, *}$ \\ ${ }^{1}$ Department of Diabetes, Monash University Central, Clinical School, Melbourne, VIC, Australia \\ 2Department of Pathology, Zunyi Maternity and Child Healthcare Hospital, Zunyi, Guizhou Province, China \\ ${ }^{3}$ Department of Endocrinology and Diabetes, The Alfred Hospital, Melbourne, VIC, Australia
}

\section{Abstract}

Diabetes is a noncommunicable disease and arguably represents the greatest pandemic in human history. Diabetic kidney disease (DKD) is seen in both type 1 and type 2 diabetes and can be detected in up to $30-50 \%$ of diabetic subjects. DKD is a progressive chronic kidney disease (CKD) and is a leading cause of mortality and morbidity in patients with diabetes. Renal fibrosis and inflammation are the major pathological features of DKD. There are a large number of independent and overlapping profibrotic and pro-inflammatory pathways involved in the pathogenesis and progression of DKD. Among these pathways, the transforming growth factor- $\beta$ (TGF- $\beta$ ) pathway plays a key pathological role by promoting fibrosis. Sirtuin-1 (SIRT1) is a protein deacetylase that has been shown to be renoprotective with an anti-inflammatory effect. It is postulated that a reduction in renal SIRT1 levels could play a key role in the pathogenesis of DKD and that restoration of SIRT1 will attenuate DKD. Cell division autoantigen 1 (CDA1) synergistically enhances the profibrotic effect of TGF- $\beta$ in DKD by regulating the expression of the TGF- $\beta$ type I receptor (T $\beta \mathrm{RI}$ ). CDA1 has also been found to be an inhibitor of SIRT1 in the DNA damage response. Indeed, targeting CDA1 in experimental DKD not only attenuates diabetes-associated renal fibrosis but also attenuates the expression of key pro-inflammatory genes such as tumor necrosis factor- $\alpha$ (TNF- $\alpha$ ) and Monocyte Chemoattractant Protein-1 (MCP-1). In conclusion, there is a large body of experimental data to support the view that targeting CDA1 is a superior approach to directly targeting TGF- $\beta$ in DKD since it is not only safe but also efficacious in retarding both fibrosis and inflammation.

Keywords:

diabetic kidney Disease (DKD), diabetic nephropathy (DN), inflammation, fibrosis, TGF- $\beta$, SIRT1, CDA1

\section{Introduction}

It is estimated that diabetes affected 30.3 million people in the USA and 415 million people worldwide in 2018; this number grew to 463 million in 2019 [1] and will increase to 630 million in 2045 [2]. It is believed that approximately half of all patients with type 2 diabetes and one-third of patients with type 1 diabetes will develop diabetic nephropathy (DN) or diabetic kidney disease (DKD) [2]. Despite significant progress having been made in improving glycemic control, DKD remains a major cause of morbidity and mortality in diabetic patients. DKD in some parts of the world represents $>50 \%$ of patients requiring dialysis and/or transplantation [3]. DKD is clinically diagnosed as the presence of diabetes with impaired renal function and/or elevated urinary albumin excretion, and it is the main cause of end-stage renal disease (ESRD) in both developing and developed countries.

It is well accepted that hyperglycemia and/or its derivative factors alter many cellular signaling pathways, such as the advanced glycation end products (AGEs)/RAGE axis, oxidative stress, Rho-kinase, the diacylglycerol (DAG)-protein kinase C (PKC), polyol, and hexosamine pathways. Increased glucose metabolism results in the excessive production of free radicals, such as reactive oxygen species (ROS). ROS-induced oxidative stress causes DNA damage, specifically strand breakage and base alterations, which activate p53 and its downstream pathways to induce cell cycle arrest or apoptosis [4]. Specific DNA damage in mitochondria results in mitochondrial dysfunction, which in turn generates more ROS. These pathways ultimately lead to a pro-inflammatory response. An increasing number of studies suggest that inflammation, together with oxidative stress and fibrosis, is a key component that plays an important role in the progression of DKD [5]. Fibrosis is the key structural hallmark of DKD, which is commonly observed in association with inflammation. In the last two decades, transforming growth factor- $\beta$ (TGF- $\beta$ ) has been identified to be a key profibrotic stimulus in the pathogenesis of DKD, and various newly discovered factors have been identified to play significant roles in the inflammatory response. Recently, several molecules involving the TGF- $\beta$ pathway, such as sirtuin-1 (SIRT1), [6] PTEN, [7] Klotho, [8, 9] BMP7 [10, 11], and cell division autoantigen 1 (CDA1) [12, 13] as well as the functional interactions among some of these molecules, were identified and found to play potential roles in the pathogenesis of $\mathrm{DKD}$, thereby providing novel potential targets to reduce the burden of DKD.

In this review, we summarize the relevant key pathways/ cellular events involved in renal inflammation and fibrosis. The two major features of DKD are presented in the Sections "Inflammation in DKD" and "Fibrosis in DKD," respectively. The interactive relationship between renal inflammation and fibrosis and the molecules/pathways linking both are also discussed. 


\section{Pathophysiology of DKD}

The pathophysiology of DKD is complex. Diabetes causes glomerular hypertension by reducing afferent arteriolar resistance [14]. Hyperglycemia and hypertension gradually lead to glomerular mesangial expansion, which is associated with endothelial dysfunction and further hemodynamic changes. The loss of electric charge and thickening of the glomerular basement membrane, as well as a decreased number of podocytes, impaired podocyte foot process effacement, and mesangial distension, are key features of the initial glomerular injury, which is considered to be critical in the development of diabetes-associated glomerulosclerosis [15].

Alterations in renal tubular function occur in the early stage of diabetes and are often related to the degree of glycemic control. In diabetes, there is a high filtered load of glucose and reabsorption of both glucose and sodium is increased as a result of the upregulation of sodium-glucose cotransporter 2 (SGLT2) in the proximal tubule. These changes ultimately lead to dilatation of afferent arteriole as a result of tubuloglomerular feedback, [16] occurring due to reduced-sodium delivery to the macula densa. Furthermore, interactions among mediators produced by endothelial cells are disrupted. In the endothelium, there is often increased endothelin-1 (ET-1) secretion, arguably the most potent vasoactive peptide, leading to vasoconstriction and vascular dysfunction $[16,17]$. In the kidney, activation of endothelin-receptor A mediated by its ligand ET-1 is not only associated with vasoconstriction but also podocyte injury, oxidative stress, inflammation, and fibrosis [18]. On the other hand, hyperglycemia, insulin resistance, and compensatory hyperinsulinemia independently cause endothelial dysfunction by promoting certain intracellular processes. These include the production of ROS, activation of PKC, generation of AGEs, enhanced oxidative stress, hypoxia, metabolic and energetic disturbances, overactivation of the renin-angiotensin-aldosterone system (RAAS), and the production of inflammatory and fibrotic factors, including TGF- $\beta 1[16,19,20]$. Activation of the intrarenal RAAS aggravates the deterioration of DKD, which has been proven in both animal models and randomized clinical trials [21]. Both TGF- $\beta 1$ and angiotensin II (Ang II) are involved in the processes that promote renal tissue fibrosis and are also associated with renal tubule dysfunction and atrophy, a reduction in the number of small vessels known as rarefaction, and chronic hypoxia [22]. Aldosterone is also thought to play an important role in the pathophysiology of $\mathrm{DKD}$, through upregulation of pro-sclerotic growth factors, such as plasminogen activator inhibitor 1 (PAI- 1 ) and TGF- $\beta$, and promotion of macrophage infiltration and consequent renal fibrosis [23]. Moreover, persistent hyperglycemia leads to endothelial cell apoptosis through the Nuclear factor kappa-light-chain-enhancer of activated $\mathrm{B}$ cells (NF-kB) and c-Jun pathways, resulting in capillary rarefaction, hypoxia, and renal fibrosis [4, 24].

In the early phase of DKD, increased glucose reabsorption, hypertrophy of the proximal tubule cells, increased oxidative stress, and increased TGF- $\beta$ production are well-documented. These changes lead to downregulation of cell division of proximal tubule cells and promote interstitial inflammation and fibrosis $[25,26]$. During DKD, endothelial nitric oxide synthase
(eNOS), which is responsible for the production of nitric oxide (NO), is uncoupled. NO, a relaxation factor that dilates the afferent and efferent arterioles, plays an essential role in maintaining kidney function. The lower levels of NO result in lower levels of vessel dilation, rendering the kidney vasculature more sensitive to vasoconstriction mediated by other factors, such as ET-1 [27]. These hemodynamic changes may also predispose DKD patients to acute kidney injury (AKI) [28].

There is an increasing interest in the role of epigenetic pathways in DKD as a potential explanation for the gene/environment interactions that have been liked to this complication [29]. This includes the potential role of DNA methylation and histone modifications in influencing susceptibility and progression of diabetic complications including nephropathy.

The importance of DNA methylation is increasingly being explored [30] although key enzymes mediating this epigenetic process are yet to be shown to be appropriate renoprotective targets. In contrast, certain histone modifications, specifically histone methylation, may be worth to further exploration with seminal studies identifying Set 7 as a histone methyltransferase, which has been shown to play a key role in hyperglycemic memory $[31,32]$ and has been shown to specifically influence experimental DKD [33]. It is likely that further research in this area will help in explaining susceptibility to DKD, developing new biomarkers to predict and monitor this complication, and finally assist in identifying targets such as enzymes implicated in epigenetic pathways as potential targets for developing renoprotective drugs.

\section{Inflammation in DKD}

DKD has not been traditionally considered an inflammatory disease. Increasing evidence suggests that DKD is not only solely occurring as a result of uncontrolled hemodynamics and hyperglycemia but also a consequence of a chronically activated innate immune system and a lowgrade inflammatory state as seen in patients with diabetes $[34,35]$. Furthermore, chronic low-grade inflammation plays a causal role in the progression of obesity and insulin resistance. Thus, inflammation may be a key factor that is activated by the metabolic, biochemical, and hemodynamic derangements known to exist in the diabetic kidney. DKD is associated with both systemic and local renal inflammation with the participation of crucial inflammatory cells, key pro-inflammatory molecules, and various relevant pathways. Among the inflammatory pathways, NF-kB plays a central role through the generation of intricate regulatory circuits that include various cellular mediators, such as adhesion molecules, intracellular second messengers, microRNAs, growth and transcription factors, and cytokines [34]. The infiltration of inflammatory cells and expression of adhesion molecules and cytokines are detected in renal tissues from subjects with DKD. These inflammatory cytokines represent a group of polypeptide signaling molecules that promote autocrine, paracrine, and juxtracrine signaling as part of the innate immune response. Important 
markers of inflammation in chronic kidney disease (CKD) are C-reactive protein (CRP), interleukin-6 (IL-6), interleukin-1 (IL-1), tumor necrosis factor- $\alpha$ (TNF- $\alpha$ ), adipokines, adhesion molecules, and the CD40 ligand, all of which have been implicated in the progression and severity of CKD. These molecules are produced by various cells including lymphocytes and adipocytes, which become dysfunctional during CKD [36]. Macrophages infiltrate the kidney, and the cycle of cytokine release with further monocyte and macrophage recruitment culminates in inflammation-related structural changes. The magnitude of macrophage infiltration and the extent of mast cell degranulation are associated with the rate of loss of estimated glomerular filtration (eGFR) [37]. Experimental animal models have also provided evidence that some acute phase markers of inflammation, such as intercellular cell adhesion molecule-1 (ICAM-1) and monocyte chemoattractant protein-1 (MCP-1), may have a direct causative role in the development of DKD [34, 38].

\subsection{NF-KB}

$\mathrm{NF}-\mathrm{KB}$, a transcription factor described above, is activated by diverse stimuli, including hyperglycemia, AGEs, mechanical stress, ROS, inflammatory cytokines, Ang II, and albuminuria/proteinuria. In addition, $\mathrm{NF}-\kappa \mathrm{B}$ plays a central role in the interplay among various factors, molecules, and pathways resulting in structural alterations and functional abnormalities observed in DKD, such as activation of the renin-angiotensin system (RAS), AGEs accumulation, and nicotinamide adenine dinucleotide phosphate hydrogen (NADPH)-dependent oxidative stress $[34,38]$. In resident kidney cells, NF- $\mathrm{KB}$ is rapidly activated leading to transcription of multiple target genes, including those coding for adhesion molecules, chemokines, inflammatory cytokines, NOS, and other molecules related to inflammation and proliferation, which are all involved in the pathogenesis of DKD [39].

\subsection{JAK/STAT Pathway}

The JAK (Janus kinase) proteins are intracellular, non-receptor tyrosine kinases that transduce cytokine-mediated signals. Various cytokines act as ligands to bind with cell surface receptors leading to receptor dimerization, which brings the receptor-associated JAKs into close proximity, leading to autophosphorylation of JAKs. The autophosphorylation of the JAK proteins induces a conformational change, allowing the transduction of the intracellular signal by further phosphorylating the receptor dimer leading to the generation of binding sites for $\mathrm{SH} 2$ domain-containing proteins, such as STAT (signal transducer and activator of transcription). Upon binding of STAT to the binding site of the receptor, JAKs can phosphorylate and activate the STAT transcription factors. Upon activation, STAT molecules can dissociate from the receptor dimer and translocate to the cell nucleus, where they activate their target genes. JAK/STAT members are controlled in a classical negative-feedback loop by the suppressors of cytokine signaling (SOCS) family (SOCS1-7 and cytokine-inducible Src homology 2 protein (CIS)) [34].
It has been demonstrated that the JAK/STAT pathway plays a role in the pathogenesis of DKD through its participation in several processes, such as the hypertrophy of mesangial cells induced by Ang II and the synthesis of TGF- $\beta$, collagen IV, and fibronectin (FN) [34]. Glucose-stimulated production of ROS can activate the JAK/STAT pathway. The upregulation of JAK/STAT has been reported in the glomerular cells of patients with early DKD, and tubulointerstitial expression of various JAK and STAT isoforms increases with disease progression and correlates inversely with the GFR. Although there are several types of JAK proteins, the one primarily studied in renal and vascular tissue is JAK2 [40]. The specific mechanism whereby hyperglycemia promotes JAK2 activation has been related to the interaction between JAK2 and ROS caused by high glucose (HG). ROS enhanced the activity of JAK2, whereas the use of an inhibitor of ROS formation (diphenylene iodonium) resulted in a marked inhibition of Ang II-induced activation of JAK2 [41]. Furthermore, a selective inhibitor of JAK1 and JAK2 was observed in a Phase-2 study to reduce albuminuria in patients with DKD [42].

\subsection{Tumor Necrosis Factor- $\alpha$}

TNF- $\alpha$ is a cytokine with prominent pro-inflammatory effects. It is mainly produced by monocytes, macrophages, and T cells, and also by intrinsic kidney cells [43]. TNF- $\alpha$ is produced as a precursor, which is activated by the TNF- $\alpha$ converting enzyme [44]. There are two TNF- $\alpha$ receptors: the TNF- $\alpha$ receptor 1 (TNFR1) and TNF- $\alpha$ receptor 2 (TNFR2). While TNFR1 modulates the immune response and apoptosis, TNFR2 has been recognized as one of the pro-inflammatory mediators in glomerulonephritis [45, 46]. After binding to these receptors, TNF- $\alpha$ activates an intracellular transduction cascade, leading to the final biological actions of this cytokine, [47] with a potential role suggested in the pathogenesis of DKD. In addition, TNF- $\alpha$ can induce the formation of ROS by renal cells [48]. Experimental researchers have shown that TNF- $\alpha$ induces the activation of NADPH oxidase in isolated rat glomeruli through the activation of the $\mathrm{PKC} /$ phosphatidylinositol-3 kinase and MAPK pathways [49]. Thus, TNF- $\alpha$ prompts local ROS production, independent of hemodynamic mechanisms, resulting in alterations of the glomerular capillary wall and consequently increased albumin permeability [50]. In many clinical studies in patients with DKD, the serum and urinary concentrations of TNF- $\alpha$ are found to be elevated as compared with nondiabetic individuals and are highly correlated with the progression of DKD. These findings indicate a potential relationship between the elevated levels of this inflammatory cytokine and the development and progression of renal injury in diabetes $[51,52]$. Moreover, serum levels of TNF receptor isoforms are linked to DKD progression $[53,54]$.

\subsection{Monocyte Chemoattractant Protein-1 (MCP-1)}

Chemokines play an important role in inflammatory cell recruitment, migration, and interaction, as well as in cellular adhesion, differentiation, and tissue damage in the setting of DKD [55]. Inflammatory chemokines, such as monocyte 
chemoattractant protein-1 (MCP-1/chemokine C-C motif ligand 2 (CCL2), C-X3-C motif chemokine (CX3CL1), and CCL5/RANTES (C-C motif ligand 5/regulated on activation, normal $\mathrm{T}$ cell expressed and secreted), are upregulated in response to metabolic and hemodynamic factors in the diabetic milieu and participate in the pathogenesis of renal damage in patients with diabetes [56]. Elevated levels of MCP-1/ CCL2 have been reported in kidneys and urine from patients with DKD, and they play a role in macrophage infiltration of the glomerulus and tubulointerstitium. Ang II directly induces MCP-1/CCL2 expression, and blockade of the RAS leads to a reduction in MCP-1/CCL2 in the urine. CX3CL1 and CCL5/ RANTES are upregulated in diabetes, both within the glomerular and tubular cells and in peritubular capillaries, acting as a chemoattractant for immune cells and cellular adhesion [56]. Indeed, strategies to inhibit MCP-1/CCL2 have been shown to reduce parameters related to inflammation in relevant renal cells and animal models of renal injury, including experimental DKD [57-60]. A small study using an antagonist of MCP-1 receptors CCR2/5 recently showed a modest effect in reducing albuminuria after 12 weeks of treatment in a cohort of type 2 diabetes patients with overt DN [61].

\subsection{Adhesion Molecules}

The expression of adhesion molecules in DKD is increased in response to TNF- $\alpha, N F-\kappa B$, and hemodynamic shear stress. Adhesion molecules are upregulated in CKD patients as a consequence of both decreased clearance and increased synthesis [62]. Intercellular adhesion molecule-1 (ICAM-1 or CD 54), vascular cell adhesion molecule-1 (VCAM-1 or CD 106), endothelial cell-selective adhesion molecule (ESAM), and E-selectin are cell surface-localized factors that facilitate intercellular binding, adhesion, and intercellular communication, participating in the pathogenesis of DKD [56]. ICAM-1 exhibits high expression in resident kidney cells, and elevated urinary levels of ICAM-1 are correlated to DKD progression [63, 64]. High circulating levels of soluble forms of VCAM-1 and ICAM-1 are also related to the progression of DKD from microalbuminuria to macroalbuminuria. ESAM reduces glomerular permeability and its downregulation in early DKD may promote albuminuria, whereas soluble levels of E-selectin are positively correlated with albuminuria and cardiovascular disease. VCAM-1 expression is increased in the kidneys of patients with DKD[65] and animal models of DKD $[66,67]$. During diabetes, VCAM-1 expression is detected on vascular endothelium and infiltrating cells in the kidney.[66] Increasing plasma levels of soluble VCAM-1 are associated with the progression of albuminuria in patients with type 1 and type 2 diabetes [68,69].

\section{Fibrosis in DKD}

Renal fibrosis is often the final common response to injury that leads to the progression of DKD and eventually ESRD. Over more than three decades, a link between mesangial matrix expansion and progression of DKD was demonstrated by a finding that measures of mesangial expansion strongly predicted the clinical manifestations of DKD [70]. Progression of DKD is evidenced by the loss of renal cells and their replacement by extracellular matrix (ECM) in glomeruli and interstitium [71, 72]. Fibrosis is characterized by myofibroblast proliferation and is a condition of excessive accumulation of ECM[73, 74] resulting from the excessive synthesis and decreased breakdown of the ECM, accompanied by an uncontrolled inflammatory response [75].

TGF- $\beta$ is the primary driver of tissue fibrosis in DKD and indeed in other forms of CKDs [76]. Mechanisms of TGF- $\beta$ 's profibrotic action in DKD are multifactorial and involve: (1) overexpression of ECM, (2) decreased degradation of ECM, (3) enhanced cross-linking between collagen and elastin fibers, and (4) overactivation of proximal tubular and endothelial cell de-differentiation. Activation of TGB- $\beta$ leads to activation of myofibroblasts, excessive production of ECM, and inhibition of ECM degradation [76]. ECM primarily contains FN and collagen IV and subsequently serves as a scaffold for the deposition of other proteins, such as collagen type I and type III, which are known as fibrillar collagens [77]. Tubular cell apoptosis and atrophy, lymphocyte and macrophage infiltration, tubular epithelial cell and endothelial cell trans-differentiation, and peritubular vasculature rarefaction are also observed in the fibrotic kidney and could also contribute to the progressive loss of renal function $[78,79]$. The reduction in TGF- $\beta$ bioactivity reduces ECM deposition and attenuates the development of fibrosis in experimental renal injury [80]. Neutralizing all the three mammalian TGF- $\beta$ isoforms $(-\beta 1,-\beta 2$, and $-\beta 3)$ with antibodies has been reported to reduce expression of ECM genes (FN and type IV collagen) and attenuates renal fibrosis in mice with type 1 or type 2 diabetes [81, 82]. Thus, TGF- $\beta$ plays a critical role in ECM accumulation in DKD. Studies on TGF- $\beta$ inhibition in animal models of kidney diseases have suggested the importance of an anti-TGF- $\beta$ strategy in ameliorating fibrotic changes [83]. However, direct targeting TGF- $\beta$, for example, using a TGF- $\beta$ neutralizing antibody, appears to be technically difficult and a clinical trial involving such an approach failed to show renoprotection [84].

Connective tissue growth factor (CTGF or CCN2) is a downstream effector induced by TGF- $\beta$ as part of the fibrosis process. Studies in animal models suggest that CTGF expression in the diabetic kidney is likely to be a key event in the development of glomerulosclerosis by affecting both matrix synthesis and its turnover [85]. A phase I study of a monoclonal antibody against CTGF in humans with diabetes and microalbuminuria demonstrated safety and a small reduction in albuminuria, but larger studies do not appear to have observed significant efficacy [86]. Interestingly, a more recently presented secondary analysis of a large clinical study of patients with type 2 diabetes, the Veterans Affairs Diabetes Trial (VADT) has found that levels of CTGF are associated with and may predict future kidney dysfunction, a finding that may reignite investigation of CTGF inhibition as a potential therapy [87].

Multiple molecules play important roles in preventing the onset and progression of DKD and some of them are demonstrated to be renoprotective. Sirtuins, a family of nicotinamide adenine dinucleotide (NAD)+-dependent class III histone deacetylases, 
for example, are found to be important regulators in renal protection as they act on many pro-inflammatory and pro-fibrotic factors and regulate their activities. Mammals have seven different sirtuins, SIRT1-7. Each sirtuin plays a different role and has variable expression levels in various tissues and cells with different substrates and their own subcellular distribution. Due to the ability to target post-translational acyl modifications of various cellular substrates, sirtuins are crucial to numerous biological processes including proliferation, DNA repair, mitochondrial energy homeostasis, and antioxidant activity [88]

\section{Role of sirtuins in DKD}

Caloric restriction not only slows aging and increases lifespan but also increases insulin sensitivity [89, 90]. Dietary restriction in diabetic rat models increased SIRT1 expression in the kidney and improved renal function including albuminuria, creatinine clearance, and renal histology [91, 92]. Thus, caloric restriction activates sirtuins that are beneficial in preventing the progression of DKD. In experimental models of diabetes and some other models of renal injury, renal SIRT1 expression is significantly reduced. Restoration of SIRT1 expression attenuated renal injury in these models and SIRT1 agonists also provided beneficial effects on certain relevant metabolic parameters, such as glucose tolerance, fasting blood glucose levels, and insulin resistance resulting in a prolongation of animal lifespan [93-95].

The loss or injury of podocytes is considered to be a major cause of albuminuria in DKD. Multiple studies have shown that SIRT1 is necessary for the maintenance of cytoskeletal integrity and the survival of podocytes [96, 97]. SIRT1 mediates this process through the deacetylation of cortactin, which plays an important role in the maintenance of the actin cytoskeleton in podocytes [96]. Studies have proven that AGE accumulation downregulates SIRT1 in podocytes, which causes increased acetylation of $\mathrm{FoxO} 4$ resulting in apoptosis of podocytes. Moreover, the interplay between SIRT1 and Forkhead Box (Fox) protein O1 (FoxO1) FoxO1 increases the expression of antioxidant enzymes such as Mn-SOD and catalase (CAT) and thereby modulates ROS accumulation [98, 99]. In addition, the SIRT1 agonist, resveratrol, increases SOD activity and reduces malondialdehyde (MDA), collagen IV, and FN expression by increasing FoxO1 activity [100]. SIRT1 deacetylates FoxO3a, which enhances FoxO3a-induced autophagy and exerts antioxidant effects while suppressing FoxO3a-induced cell death. SIRT1 activates autophagy by deacetylating $\mathrm{FoxO} 1$ and $\mathrm{FoxO} 3 a$ in the nucleus [101-103]. SIRT1 in tubules downregulates claudin-1 expression in podocytes to protect against diabetes-induced albuminuria [104, 105]. SIRT1 downregulates the expression of claudin- 1 by deacetylating histone $\mathrm{H} 3$ and $\mathrm{H} 4$.

SIRT1 can deacetylate the p65 subunit of NF-kB and inhibit NF- $\kappa B$ 's pro-inflammatory signaling and the downstream production of MCP-1, ICAM-1, and VCAM-1 [106-108]. In the $\mathrm{db} / \mathrm{db}$ mouse model, deletion of SIRT1 in the podocytes of these diabetic mice results in acetylation of the p65 subunit of
NF- $\mathrm{B}$ B and STAT3, leading to increased levels of albuminuria [109]. Diabetes-induced downregulation of SIRT1 leading to activation of NF- $\mathrm{KB}$ signaling also inhibits the anti-oxidative stress Nrf2/ARE pathway. Podocyte-specific ablation of SIRT1 in $\mathrm{db} / \mathrm{db}$ mice results in severe proteinuria and kidney injury, which are accompanied by greater acetylation of $p 65$ and STAT3 [109]. NF- $\mathrm{BB}$ directly regulates NOX4 expression by binding to its promoter. Downregulation of NF- $\kappa B$ results in reduced NOX4 expression, which ultimately protects against DKD since NOX4 plays a key role in promoting renal oxidative stress and ultimately DKD [110, 111].

Recent research has demonstrated a role for SIRT1 in proximal tubule-podocyte communication in association with the SGLT2. In the diabetic kidney, HG levels within the proximal tubules will trigger glucose transporter 2 (GLUT2)-mediated intracellular glucose uptake via SGLT2 upregulation, causing an associated decrease in SIRT1 [88].

The diabetes-induced decrease in SIRT1 promotes apoptosis in podocytes, ECs, and tubular epithelial cells by the activation of the p53 pathway; and this effect is postulated to cause albuminuria and renal dysfunction in DKD. Acetylation of p53 stabilizes and activates p53 and promotes pro-apoptotic gene transcription, including that of p21 and Bcl-2associated $X$ protein (Bax). SIRT1 negatively regulates p53 by deacetylating specific residues of p53 [112]. Proximal tubular cells (PTCs) in a HG condition have reduced SIRT1 protein expression, increased expression of c-caspase- 3 and c-PARP, and increased acetylation of p53 [113]. In addition, resveratrol treatment restores SIRT1 and prevents increases in expression of p38 and p53, PTC apoptosis, and albuminuria in DKD [113, 114]. A p53/miR-155-5p/SIRT1 pathway has been described in the kidney of animals with DKD, where p53 promotes the expression of miR-155-5p, which reduces SIRT1 expression and promotes p53 activity [115].

The targeted deletion of SIRT1 in proximal tubules of DKD mice results in ectopic expression of the tight junction protein claudin-1 in podocytes, an event that leads to albuminuria and renal functional impairment in streptozotocin (STZ)induced diabetic mice [104]. These effects were abolished in podocytes exposed to conditional medium from PTCs overexpressing SIRT1, even under HG conditions. These findings reflect the existence of protective factors secreted from SIRT1 overexpressing tubular cells. This functional relationship between proximal tubules and podocytes is referred to as "proximal tubule-podocyte communication."[104] Also, SIRT1 modulates angiogenesis through downregulation of vascular endothelial growth factor (VEGF) and Flk-1 (VEGFR-2) expression in HG-treated podocytes and endothelial cells [116].

HIF-1 $\alpha$ is a downstream target of SIRT1, and during hypoxia, downregulation of SIRT1 leads to greater acetylation and activation of HIF-1 $\alpha$. SIRT1 deficiency under diabetic conditions leads to activation of HIF- $1 \alpha$, which results in abnormal angiogenesis and fibrosis in the kidney. SIRT1 was also found 
to attenuate renal inflammation and fibrosis under hyperglycemic conditions through inhibition of $\mathrm{HIF}-1 \alpha$ signaling in mesangial cells [117]. Recent studies have demonstrated that hypoxia is also involved in the pathogenesis of DKD [14, 118]. Metabolic changes in diabetic kidneys cause excessive oxygen consumption, resulting in hypoxia and expression of the oxygen sensor HIF-1 $\alpha$. When SIRT1 expression is restored using resveratrol, $\mathrm{HIF}-1 \alpha$ is deacetylated and inactivated, which prevents the expression of downstream inflammatory factors [118].

AMP-activated protein kinase (AMPK) and SIRT1 have been identified as intracellular energy sensors, detecting and responding to $\mathrm{NAD}^{+} / \mathrm{NADH}$ ratios. They are activated under conditions of energy depletion and are deactivated in diabetes [119-121]. In hyperglycemic conditions, the downregulation of AMPK/SIRT1/PGC-1 $\alpha$ signaling induces hypertrophy, oxidative stress, and mitochondrial and autophagy dysfunction, which all promote the development of DKD. SIRT1 deacetylates lysine residues in liver kinase B1 (LKB1) which catalyzes the phosphorylation and activation of AMPK and downstream signaling [122]. Glucose restriction-induced activation of AMPK increases the activity of SIRT1 by promoting the transcription of the $\mathrm{NAD}^{+}$biosynthetic enzyme nicotinamide phosphoribosyltransferase (NAMPT) [123].

An increasing body of evidence indicates that defective autophagy contributes to the pathogenesis of DKD [124]. Both the AMPK and mTOR pathways regulate autophagy. A decrease in SIRT1 expression inhibits autophagy under diabetic conditions by suppressing the expression of autophagy-related proteins, FOXO and AMPK, and by activating mTOR. Restored SIRT1 increases the expression of FoxO3, which positively regulates BNIP3, and thus enhances autophagy in the kidneys of $\mathrm{db} / \mathrm{db}$ mice [125]. SIRT1 can attenuate diabetes-related renal fibrogenesis by inhibiting the TGF- $\beta 1 /$ small mothers against decapentaplegic (Smad) homolog $2 / 3$ pathway when its expression level is restored. The pro-fibrogenic factor TGF- $\beta 1$ is upregulated in DKD and activates the downstream mediators Smad2/3 [126, 127]. Phosphorylation and acetylation of Smad2/3 enhance their activity and cause accumulation of ECM [126-128]. However, Smad2/3 have also been identified as targets of SIRT1. Furthermore, resveratrol treatment, to restore the level of SIRT1, deacetylates Smad3 [129].

The associations of sirtuins other than SIRT1 with DKD have also been explored. SIRT3 overexpression suppresses HG-induced apoptosis by reducing ROS accumulation through modulation of Akt/FoxO signaling in PTCs [130]. Furthermore, in mice with DN, the activation of SIRT3 through the $G$ protein-coupled bile acid receptor prevents oxidative stress and lipid accumulation [131]. The restoration of renal SIRT3 protein expression in rats with high-fatdiet-induced DKD has proven to be renoprotective against oxidative stress. On the other hand, SIRT3 suppression is associated with the activation of TGF- $\beta / S m a d 3$ signaling and increased HIF-1 $\alpha$ accumulation, which subsequently causes abnormal glycolysis in PTCs and promotes kidney fibrosis in diabetic mice [132]. SIRT4 overexpression leads to downregulation of apoptosis-related proteins such as NADPH oxidase 1 (NOX1), Bax, and phosphorylated $\mathrm{p} 38$, along with upregulation of $\mathrm{Bcl}-2$. These findings are associated with attenuation of the inflammatory response in HG-simulated podocytes.[133] SIRT6 deletion exacerbates podocyte injury in diabetic mice, and SIRT6 overexpression with HG treatment has been reported to protect against podocyte injury through epigenetic regulation of Notch1 and Notch4 transcription due to deacetylation of H3K9 [134]. SIRT6 was also found to regulate the immune response by activating M2 macrophages, which are protective against podocyte injury, in STZ-induced diabetic mice [135]. In a recent study, selective deletion of NAMPT in proximal tubule cells of STZ-induced diabetic mice led to downregulation of SIRT6. This was accompanied by thickening of the tubular basement membrane, type IV collagen deposition, enhanced renal fibrosis, and albuminuria. Selective deletion of SIRT6 in the proximal tubules of diabetic mice caused a phenotype similar to that seen in NAMPT knockout mice. Therefore, the NAMPT-SIRT6 axis in proximal tubules has been suggested to be a key player in the fibrogenic ECM remodeling associated with DN [133].

Because sirtuins maintain important gatekeeping roles in the control of the cell proteome, $[136,137]$ their function must be tightly controlled. Indeed, each sirtuin is specifically regulated by a rich array of factors in a cell- and tissue-specific manner. Sirtuins are extensively controlled at multiple levels and have been extensively discussed previously [138]. A recent study shows that CDA1 is a negative regulator of SIRT1.[139] Since CDA1 is a key TGF- $\beta$ enhancer in DKD and a promising target to reduce DKD, the newly known effect of CDA1 on SIRT1 may be able to shed light on the mechanisms whereby CDA1 could be implicated in the pathogenesis of DKD.

\section{Actions of CDA1 in DKD}

CDA1 was initially identified as an autoantigen reactive with an autoimmune serum from a patient with discoid lupus erythematosus [140]. CDA1 is encoded by the gene Testis-specific Y-encoded-like protein 2 (TSPYL2), which is located on the X-chromosome [141]. CDA1 is also known as cutaneous T-cell lymphoma-associated antigen se20-4, [142] NP79, [143] differentially expressed nucleolar TGF$\beta 1$ target (DENTT), which was found to be upregulated by TGF- $\beta 1$ treatment in lung cancer cells [144]. Later, CASKinteracting nucleosome assembly protein (CINAP) was identified as the mouse homolog of CDA1 [145]. CDA1 acts as an antiproliferative protein via p53/p21, certain cyclins, and cyclin-dependent kinases as well as influencing the ERK/ MAPK and TGF- $\beta$ pathways [54]. In renal and vascular cells, CDA1 has been shown by our group to synergistically enhance TGF- $\beta$ signaling in human and rodent cells, and indeed, to play a critical pathological role in experimental 


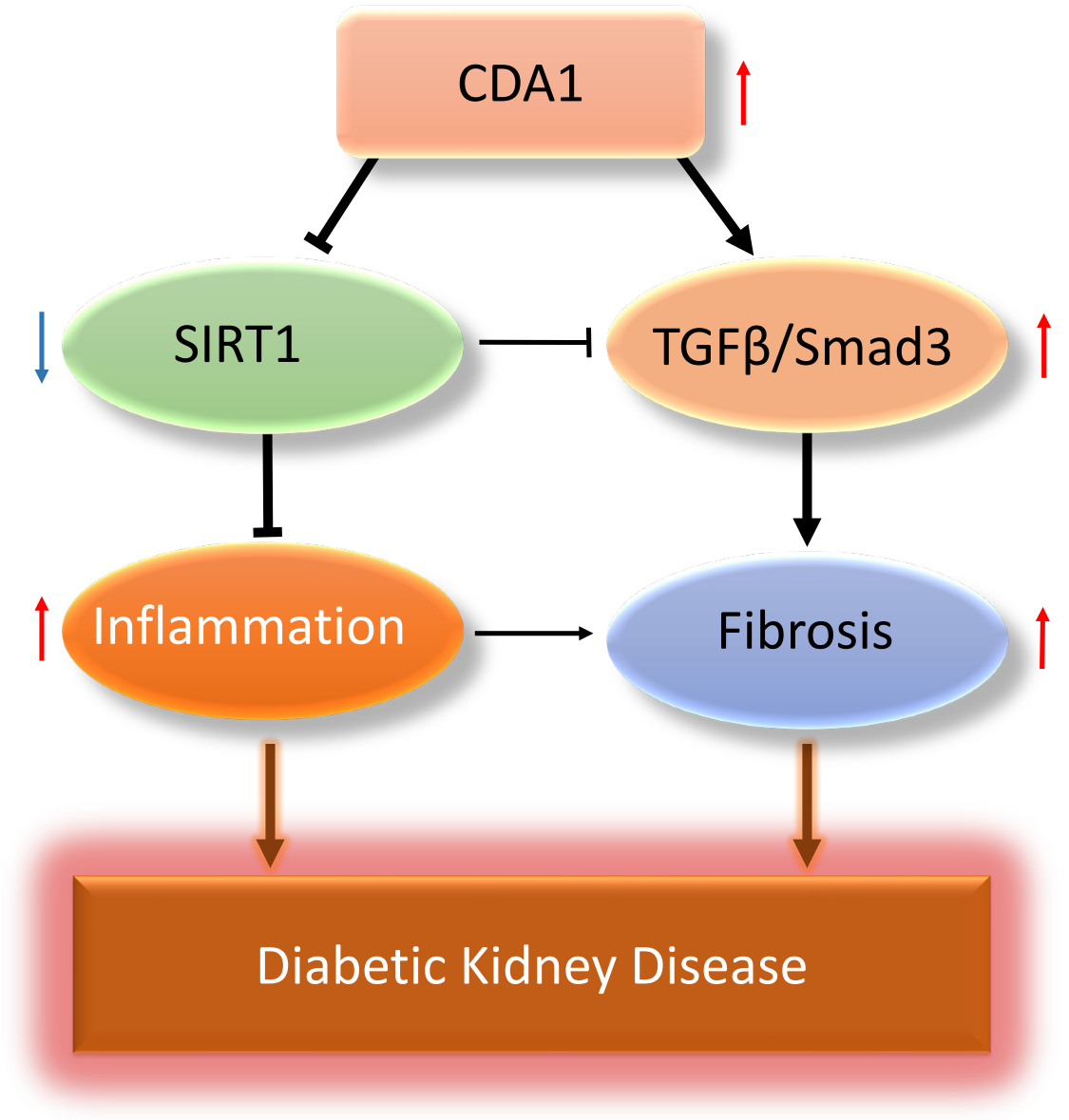

Figure 1. Schematic diagram showing the relationships of CDA1 with profibrotic and anti-inflammatory pathways in the pathogenesis of DKD. $C D A 1$ expression is elevated in DKD. CDA1 enhances the TGF- $\beta / S m a d 3$ signaling pathway by increasing T RRI levels, leading to increased fibrosis. CDA1 can negatively regulate SIRT1, a renoprotective protein deacetylase which is known to be downregulated

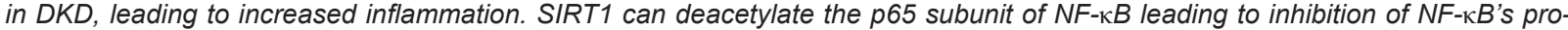
inflammatory signaling and the downstream production of pro-inflammatory molecules such as MCP-1, ICAM-1, and VCAM-1. SIRT1 is also known to deacetylate Smad3 leading to inhibition of Smad3-mediated TGF- $\beta$ signaling and thus reduction of fibrosis. CDA1, cell division autoantigen 1; DKD, diabetic kidney disease; ICAM-1, intercellular adhesion molecule-1; MCP-1, monocytes chemoattractant protein-1; SIRT1, sirtuin-1; Smad3, small mothers against decapentaplegic 3; T $\beta R$ I, TGF- $\beta$ type I receptor; TGF- $\beta$, transforming growth factor- $\beta$; VCAM-1, vascular cell adhesion molecule-1.

DKD in mice $[12,13,146]$. CDA1 expression levels are significantly elevated in animal models of DKD and this change has been confirmed in renal biopsy samples from patients with DKD, demonstrating its relevance to human DKD [146].

Although recent findings by our group highlight the role of CDA1 in the pathophysiology of CKD, the detailed molecular mechanisms are yet to be fully elucidated. CDA1 expression is elevated in sites of end-organ injury in diabetes [12, 13]. CDA1 expression is stimulated by various factors, such as TGF- $\beta$ and the DNA damage response, and is suppressed by DNA methylation and endogenous NO [12, 139, 144, 147-149]. An in vivo study suggested that the elevated expression levels of CDA1 in the diabetic mouse model are accompanied by increased levels of TGF- $\beta$ signaling and ECM accumulation. In in vitro conditions, TGF- $\beta$ treatment rapidly increases CDA1 expression and amplifies TGF- $\beta$ signaling leading to upregulation of various ECM genes. CDA1 is also reported to upregulate TGF- $\beta$ type I receptor (T $\beta R \mathrm{R}$ ) expression. Knockdown of CDA1 not only reduces $T \beta R I$ expression but is also sufficient to inhibit the profibrotic effect of TGF- $\beta$, leading to downregulation of sclerotic genes such as CTGF, collagens I, III, IV, and FN $[12,13]$. CDA1 gene knockout does not completely block the TGF- $\beta$-dependent Smad3 signaling pathway but significantly reduces Smad3 phosphorylation and its transcriptional activity.

Interestingly, diabetic CDA1 knockout mice show an attenuated expression of pro-inflammatory genes, such as TNF- $\alpha$, MCP1, CRP, ICAM-1, and VCAM-1 accompanied by a marked reduction in ECM accumulation [146]. These findings were further corroborated by studies with a cell-permeable synthetic peptide, which was used to inhibit the activity of CDA1 in diabetic ApoE knockout mice. This led to a marked reduction in not only TGF- $\beta$ signaling and renal fibrosis in these mice but also pro-inflammatory gene expression [150]. 
A recent study[139] has shown that CDA1 acts as a negative regulator of SIRT1. Furthermore, CDA1-dependent inhibition of SIRT1 leads to increased p53 acetylation as well as intracellular accumulation and increased activity of p53 in the DNA damage response [147]. This finding provides a mechanistic explanation for the observed effect of targeting CDA1 on pro-inflammatory genes in experimental DKD as discussed in Figure 1. SIRT1 is downregulated in DKD, which can, at least partially, occur as a result of an increased level of CDA1. Therefore, it is hypothesized that targeting CDA1 would restore the level of SIRT1, leading to downregulation of various pro-inflammatory genes.

\section{Conclusion}

In summary, diabetes is a growing pandemic globally with a large number of people affected by the deadly complication,
DKD. A large array of molecules and pathways are involved in the pathogenesis of DKD. The major pathological features of DKD are inflammation and fibrosis. TGF- $\beta$ has been considered to play a key profibrotic role in the pathogenesis of DKD and several molecules, such as SIRT1, are known to be renoprotective. However, molecules such as SIRT1 are usually downregulated when the kidney is injured in diabetes. SIRT1 can influence numerous pathways in DKD and has anti-inflammatory effects. CDA1 has been shown to pathologically enhance TGF- $\beta$ signaling leading to renal fibrosis and can negatively regulate SIRT1 (Figure 1). Targeting CDA1 leads to attenuation of renal fibrosis as well as reducing the expression of pro-inflammatory genes in experimental DKD. Therefore, targeting CDA1 in DKD would have effects in reducing TGF- $\beta$ signaling and restoring SIRT1, presumably leading to a reduction in both renal fibrosis and inflammation, thereby representing a potentially superior novel approach to retard and/or reverse DKD.

\section{Acknowledgments}

This work is supported by the Australian National Health and Medical Research Council (NHMRC) grant APP1175760.

Conflicts of Interest

Mark E. Cooper is a Co-Editor-in-Chief of the journal, and Zhonglin Chai is a board member. All the authors have no other conflicts of interest to disclose.

Author Contributions

$D P, M C$, and ZC designed the structure of the paper. DP and ZC drafted the manuscript. YY, KS, and TW read, edited, and provided their input. MC and ZC finalized the paper and all the authors approved the final version to be published.

\section{REFERENCES}

[1] Saeedi P, Petersohn I, Salpea P, Malanda B, Karuranga S Unwin N, et al. Global and regional diabetes prevalence estimates for 2019 and projections for 2030 and 2045: Results from the international diabetes federation diabetes atlas, $9^{\text {th }}$ edition. Diabetes Res Clin Pract 2019; 157:107843.

[2] Cho $\mathrm{NH}$, Shaw JE, Karuranga S, Huang $\mathrm{Y}$, da Rocha Fernandes JD, Ohlrogge AW, et al. IDF diabetes atlas: Global estimates of diabetes prevalence for 2017 and projections for 2045. Diabetes Res Clin Pract 2018; 138:271-81.

[3] Patel DM, Bose M, Cooper ME. Glucose and blood pressure-dependent pathways-the progression of diabetic kidney disease. Int J Mol Sci 2020; 21, 2218

[4] Sifuentes-Franco S, Padilla-Tejeda DE, Carrillo-Ibarra S, Miranda-Díaz AG. Oxidative stress, apoptosis, and mitochondrial function in diabetic nephropathy. Int J Endocrinol 2018; 2018:1875870.

[5] Donate-Correa J, Luis-Rodriguez D, Martin-Nunez E, Tagua VG, Hernandez-Carballo C, Ferri C, et al. Inflammatory targets in diabetic nephropathy. J Clin Med 2020; 9, 458.

[6] Wang W, Sun W, Cheng Y, Xu Z, Cai L. Role of sirtuin-1 in diabetic nephropathy. J Mol Med (Berl) 2019; 97:291-309.

[7] Li Y, Hu Q, Li C, Liang K, Xiang Y, Hsiao H, et al. Pten-induced partial epithelial-mesenchymal transition drives diabetic kidney disease. J Clin Invest 2019: 129:1129-51.

[8] Navarro-Gonzalez JF, Sanchez-Nino MD, Donate-Correa J, Martin-Nunez E, Ferri C, Perez-Delgado N, et al. Effects of pentoxifylline on soluble klotho concentrations and renal tubular cell expression in diabetic kidney disease. Diabetes Care 2018; 41:1817-20.

[9] Takenaka T, Kobori H, Miyazaki T, Suzuki H, Nishiyama A, Ishii $\mathrm{N}$, et al. Klotho protein supplementation reduces blood pressure and renal hypertrophy in $\mathrm{db} / \mathrm{db}$ mice, a model of type 2 diabetes. Acta Physiol (Oxf) 2019; 225:e13190.

[10] Wang SN, Lapage J, Hirschberg R. Loss of tubular bone morphogenetic protein-7 in diabetic nephropathy. J Am Soc Nephrol 2001; 12:2392-9.

[11] Wang S, Chen Q, Simon TC, Strebeck F, Chaudhary L, Morrissey J, et al. Bone morphogenic protein-7 (BMP-7), a novel therapy for diabetic nephropathy. Kidney Int 2003; 63:2037-49.

[12] Pham Y, Tu Y, Wu T, Allen TJ, Calkin AC, Watson AM, et al. Cell division autoantigen 1 plays a profibrotic role by modulating downstream signalling of TGF-beta in a murine diabetic model of atherosclerosis. Diabetologia 2010; 53:170-9.

[13] Tu Y, Wu T, Dai A, Pham Y, Chew P, de Haan JB, et al. Cell division autoantigen 1 enhances signaling and the profibrotic effects of transforming growth factor-beta in diabetic nephropathy. Kidney Int 


\section{1; 79:199-209.}

[14] McCarty MF. Adjuvant strategies for prevention of glomerulosclerosis. Med Hypotheses 2006; 67:1277-96.

[15] Lopez-Novoa JM, Martinez-Salgado C, Rodriguez-Pena AB, Lopez-Hernandez FJ. Common pathophysiological mechanisms of chronic kidney disease: Therapeutic perspectives. Pharmacol Ther 2010; 128:61-81.

[16] Lin YC, Chang YH, Yang SY, Wu KD, Chu TS. Update of pathophysiology and management of diabetic kidney disease. J Formos Med Assoc 2018: 117:662-75.

[17] Potenza MA, Gagliardi S, Nacci C, Carratu MR, Montagnani M. Endothelial dysfunction in diabetes: From mechanisms to therapeutic targets. Curr Med Chem 2009; 16:94-112.

[18] de Zeeuw D, Coll B, Andress D, Brennan JJ, Tang H, Houser $\mathrm{M}$, et al. The endothelin antagonist atrasentan lowers residual albuminuria in patients with type 2 diabetic nephropathy. J Am Soc Nephrol 2014; 25:1083-93.

[19] Sharma D, Bhattacharya P, Kalia K, Tiwari V. Diabetic nephropathy: New insights into established therapeutic paradigms and novel molecular targets. Diabetes Res Clin Pract 2017; 128:91-108.

[20] Warren AM, Knudsen ST, Cooper ME. Diabetic nephropathy: An insight into molecular mechanisms and emerging therapies. Expert Opin Ther Targets 2019; 23:579-91.

[21] Gurley SB, Coffman TM. The renin-angiotensin system and diabetic nephropathy. Semin Nephrol 2007; 27:144-52.

[22] He J, Xu Y, Koya D, Kanasaki K. Role of the endothelial-to-mesenchymal transition in renal fibrosis of chronic kidney disease. Clin Exp Nephrol 2013; 17:488-97.

[23] Ritz E, Tomaschitz A. Aldosterone, a vasculotoxic agent novel functions for an old hormone. Nephrol Dial Transplant 2009; 24:2302-5

[24] Cheng AS, Cheng $\mathrm{YH}$, Chiou $\mathrm{CH}$, Chang TL. Resveratrol upregulates Nrf2 expression to attenuate methylglyoxal-induced insulin resistance in Hep G2 cells. J Agric Food Chem 2012; 60:9180-7

[25] Chevalier RL. The proximal tubule is the primary target of injury and progression of kidney disease: Role of the glomerulotubular junction. Am J Physiol Renal Physiol 2016; 311:F145-61.

[26] Vallon V. The proximal tubule in the pathophysiology of the diabetic kidney. Am J Physiol Regul Integr Comp Physiol 2011; 300:R1009-22.

[27] Cheng H, Harris RC. Renal endothelial dysfunction in diabetic nephropathy. Cardiovasc Hematol Disord Drug Targets 2014; 14:22-33. [28] Yu SM, Bonventre JV. Acute kidney injury and progression of diabetic kidney disease. Adv Chronic Kidney Dis 2018; 25: $166-180$.

[29] Cooper ME, El-Osta A. Epigenetics: Mechanisms and implications for diabetic complications. Circ Res 2010; 107:1403-13.

[30] Pirola L, Balcerczyk A, Tothill RW, Haviv I, Kaspi A, Lunke S, et al. Genome-wide analysis distinguishes hyperglycemia regulated epigenetic signatures of primary vascular cells. Genome Res 2011; 21:1601-15.

[31] El-Osta A, Brasacchio D, Yao D, Pocai A, Jones PL, Roeder RG et al. Transient high glucose causes persistent epigenetic changes and altered gene expression during subsequent normoglycemia J Exp Med 2008; 205:2409-17.

[32] Okabe J, Orlowski C, Balcerczyk A, Tikellis C, Thomas MC
Cooper ME, et al. Distinguishing hyperglycemic changes by Set7 in vascular endothelial cells. Circ Res 2012; 110:1067-76.

[33] Sun G, Reddy MA, Yuan H, Lanting L, Kato M, Natarajan R. Epigenetic histone methylation modulates fibrotic gene expression. J Am Soc Nephrol 2010; 21:2069-2080.

[34] Garcia-Garcia PM, Getino-Melian MA, Dominguez-Pimentel V, Navarro-Gonzalez JF. Inflammation in diabetic kidney disease. World J Diabetes 2014; 5:431-43.

[35] Pickup JC. Inflammation and activated innate immunity in the pathogenesis of type 2 diabetes. Diabetes Care 2004; 27:813-23.

[36] Roubicek T, Bartlova M, Krajickova J, Haluzikova D, Mraz M, Lacinova $Z$, et al. Increased production of proinflammatory cytokines in adipose tissue of patients with end-stage renal disease. Nutrition 2009; 25:762-8.

[37] Alicic RZ, Johnson EJ, Tuttle KR. Inflammatory mechanisms as new biomarkers and therapeutic targets for diabetic kidney disease. Adv Chronic Kidney Dis 2018; 25:181-91.

[38] Donate-Correa J, Martin-Nunez E, Muros-de-Fuentes M, Mora-Fernandez C, Navarro-Gonzalez JF. Inflammatory cytokines in diabetic nephropathy. J Diabetes Res 2015; 2015:948417.

[39] Guijarro C, Egido J. Transcription factor-kappa b (NF-kappa B) and renal disease. Kidney Int 2001; 59:415-24.

[40] Brosius FC, 3rd, Banes-Berceli A. A new pair of SOCS for diabetic nephropathy. J Am Soc Nephrol 2010; 21:723-4.

[41] Li R, Yang N, Zhang L, Huang Y, Zhang R, Wang F, et al. Inhibition of Jak/STAT signaling ameliorates mice experimental nephrotic syndrome. Am J Nephrol 2007; 27:580-9.

[42] Brosius FC, Tuttle KR, Kretzler M. Jak inhibition in the treatment of diabetic kidney disease. Diabetologia 2016; 59:1624-7.

[43] Jevnikar AM, Brennan DC, Singer GG, Heng JE, Maslinski W, Wuthrich RP, et al. Stimulated kidney tubular epithelial cells express membrane associated and secreted TNF alpha. Kidney Int 1991; 40:203-11.

[44] Wang X, Feuerstein GZ, Xu L, Wang H, Schumacher WA, Ogletree $\mathrm{ML}$, et al. Inhibition of tumor necrosis factor-alpha-converting enzyme by a selective antagonist protects brain from focal ischemic injury in rats. Mol Pharmacol 2004; 65:890-6.

[45] Zhu LJ, Yang X, Li XY, Liu QH, Tang XQ, Zhou SF, et al. Suppression of tumor necrosis factor receptor associated factor (TRAF)-2 attenuates the proinflammatory and proliferative effect of aggregated igg on rat renal mesangial cells. Cytokine 2010; 49:201-8.

[46] Vielhauer V, Stavrakis G, Mayadas TN. Renal cell-expressed TNF receptor 2, not receptor 1 , is essential for the development of glomerulonephritis. J Clin Invest 2005; 115:1199-209.

[47] Ortiz A, Bustos C, Alonso J, Alcazar R, Lopez-Armada MJ, Plaza $\mathrm{JJ}$, et al. Involvement of tumor necrosis factor-alpha in the pathogenesis of experimental and human glomerulonephritis. Adv Nephrol Necker Hosp 1995; 24:53-77.

[48] Radeke HH, Meier B, Topley N, Floge J, Habermehl GG, Resch K. Interleukin 1-alpha and tumor necrosis factor-alpha induce oxygen radical production in mesangial cells. Kidney Int 1990; 37:767-75.

[49] Koike N, Takamura T, Kaneko S. Induction of reactive oxygen species from isolated rat glomeruli by protein kinase $C$ activation and TNF-alpha stimulation, and effects of a phosphodiesterase inhibitor. Life Sci 2007; 80:1721-8.

[50] McCarthy ET, Sharma R, Sharma M, Li JZ, Ge XL, Dileepan KN, Savin VJ. TNF-alpha increases albumin permeability of isolated rat 
glomeruli through the generation of superoxide. J Am Soc Nephrol 1998; 9:433-8.

[51] Moriwaki Y, Yamamoto T, Shibutani Y, Aoki E, Tsutsumi Z, Takahashi S, et al. Elevated levels of interleukin-18 and tumor necrosis factor-alpha in serum of patients with type 2 diabetes mellitus: Relationship with diabetic nephropathy. Metabolism 2003; 52: 605-8. [52] Navarro JF, Mora C, Maca M, Garca J. Inflammatory parameters are independently associated with urinary albumin in type 2 diabetes mellitus. Am J Kidney Dis 2003; 42:53-61.

[53] Gohda T, Kamei N, Kubota M, Tanaka K, Yamashita Y, Sakuma H, et al. Fractional excretion of tumor necrosis factor receptor 1 and 2 in patients with type 2 diabetes and normal renal function. J Diabetes Investig 2020; 12:382-9.

[54] Yang Y, Shi K, Patel DM, Liu F, Wu T, Chai Z. How to inhibit transforming growth factor beta safely in diabetic kidney disease. Curr Opin Nephrol Hypertens 2021; 30:115-22.

[55] Ruster C, Wolf G. The role of chemokines and chemokine receptors in diabetic nephropathy. Front Biosci 2008; 13:944-55.

[56] Perez-Morales RE, Del Pino MD, Valdivielso JM, Ortiz A, MoraFernandez C, Navarro-Gonzalez JF. Inflammation in diabetic kidney disease. Nephron 2019; 143:12-6.

[57] Boels MGS, Koudijs A, Avramut MC, Sol W, Wang G, van Oeveren-Rietdijk AM, et al. Systemic monocyte chemotactic protein-1 inhibition modifies renal macrophages and restores glomerular endothelial glycocalyx and barrier function in diabetic nephropathy. Am J Pathol 2017; 187:2430-40.

[58] Zoja C, Corna D, Locatelli M, Rottoli D, Pezzotta A, Morigi M, et al. Effects of MCP-1 inhibition by bindarit therapy in a rat model of polycystic kidney disease. Nephron 2015; 129:52-61.

[59] Giunti S, Barutta F, Perin PC, Gruden G. Targeting the MCP-1/ CCR2 system in diabetic kidney disease. Curr Vasc Pharmacol 2010; 8:849-60.

[60] Giunti S, Pinach S, Arnaldi L, Viberti G, Perin PC, Camussi G, et al. The MCP-1/CCR2 system has direct proinflammatory effects in human mesangial cells. Kidney Int 2006; 69:856-63.

[61] Gale JD, Gilbert S, Blumenthal S, Elliott T, Pergola PE, Goteti $\mathrm{K}$, et al. Effect of PF-04634817, an oral CCR2/5 chemokine receptor antagonist, on albuminuria in adults with overt diabetic nephropathy Kidney Int Rep 2018; 3:1316-27.

[62] Bonventre JV, Colvin RB. Adhesion molecules in renal disease. Curr Opin Nephrol Hypertens 1996; 5:254-261.

[63] Lhotta K, Schlogl A, Kronenberg F, Joannidis M, Konig P. Soluble intercellular adhesion molecule-1 (ICAM-1) in serum and urine: Correlation with renal expression of ICAM-1 in patients with kidney disease. Clin Nephrol 1997; 48:85-91.

[64] Gu HF, Ma J, Gu KT, Brismar K. Association of intercellular adhesion molecule 1 (ICAM1) with diabetes and diabetic nephropathy. Front Endocrinol (Lausanne) 2012; 3:179.

[65] Seron D, Cameron JS, Haskard DO. Expression of VCAM-1 in the normal and diseased kidney. Nephrol Dial Transplant 1991; 6:917-22.

[66] Ina K, Kitamura H, Okeda T, Nagai K, Liu Z.Y, Matsuda M, et al Vascular cell adhesion molecule-1 expression in the renal interstitium of diabetic KKAY mice. Diabetes Res Clin Pract 1999; 44:1-8.

[67] Wang F, Li M, Cheng L, Zhang T, Hu J, Cao M, et al. Intervention with cilostazol attenuates renal inflammation in streptozotocin-induced diabetic rats. Life Sci 2008; 83:828-35.
[68] Clausen P, Jacobsen P, Rossing K, Jensen JS, Parving $H H$, Feldt-Rasmussen B. Plasma concentrations of VCAM-1 and ICAM-1 are elevated in patients with type 1 diabetes mellitus with microalbuminuria and overt nephropathy. Diabet Med 2000; 17:644-9.

[69] Rubio-Guerra AF, Vargas-Robles H, Lozano Nuevo JJ, Escalante-Acosta BA. Correlation between circulating adhesion molecule levels and albuminuria in type-2 diabetic hypertensive patients. Kidney Blood Press Res 2009; 32:106-9.

[70] Mauer SM, Steffes MW, Ellis EN, Sutherland DER, Brown DM, Goetz FC. Structural-functional relationships in diabetic nephropathy. Kidney Int 1984; 25:225-5.

[71] Fogo AB. Progression and potential regression of glomerulosclerosis. Kidney Int 2001; 59:804-19.

[72] Rodriguez-Pena A, Prieto M, Duwel A, Rivas JV, Eleno N, PerezBarriocanal $\mathrm{F}$, et al. Up-regulation of endoglin, a TGF-beta-binding protein, in rats with experimental renal fibrosis induced by renal mass reduction. Nephrol Dial Transplant 2001; 16 Suppl 1:34-9.

[73] Iwano M, Neilson EG. Mechanisms of tubulointerstitial fibrosis. Curr Opin Nephrol Hypertens 2004; 13:279-84.

[74] Li R, Chung AC, Dong Y, Yang W, Zhong X, Lan HY. The microRNA mir-433 promotes renal fibrosis by amplifying the TGF-beta/ Smad3-Azin1 pathway. Kidney Int 2013; 84:1129-44.

[75] el Nahas AM, Muchaneta-Kubara EC, Essawy M, Soylemezoglu O. Renal fibrosis: Insights into pathogenesis and treatment. Int J Biochem Cell Biol 1997; 29:55-62.

[76] Meng XM, Nikolic-Paterson DJ, Lan HY. TGF-beta: The master regulator of fibrosis. Nat Rev Nephrol 2016; 12:325-38.

[77] Qi W, Twigg S, Chen X, Polhill TS, Poronnik P, Gilbert RE, et al. Integrated actions of transforming growth factor-beta1 and connective tissue growth factor in renal fibrosis. Am J Physiol Renal Physiol 2005; 288:F800-9.

[78] Zeisberg M, Neilson EG. Mechanisms of tubulointerstitial fibrosis. J Am Soc Nephrol 2010; 21:1819-34.

[79] Schlondorff DO. Overview of factors contributing to the pathophysiology of progressive renal disease. Kidney Int 2008; 74:860-6.

[80] Gupta S, Clarkson MR, Duggan J, Brady HR. Connective tissue growth factor: Potential role in glomerulosclerosis and tubulointerstitial fibrosis. Kidney Int 2000; 58:1389-99.

[81] Sharma K, Jin Y, Guo J, Ziyadeh FN. Neutralization of TGF-beta by anti-TGF-beta antibody attenuates kidney hypertrophy and the enhanced extracellular matrix gene expression in STZ-induced diabetic mice. Diabetes 1996; 45:522-30.

[82] Ziyadeh FN, Hoffman BB, Han DC, Iglesias-De La Cruz MC, Hong $\mathrm{SW}$, Isono $\mathrm{M}$, et al. Long-term prevention of renal insufficiency, excess matrix gene expression, and glomerular mesangial matrix expansion by treatment with monoclonal antitransforming growth factor-beta antibody in $\mathrm{db} / \mathrm{db}$ diabetic mice. Proc Natl Acad Sci U S A 2000; 97:8015-20.

[83] Sato M, Muragaki Y, Saika S, Roberts AB, Ooshima A. Targeted disruption of TGF-beta1/Smad3 signaling protects against renal tubulointerstitial fibrosis induced by unilateral ureteral obstruction. J Clin Invest 2003; 112:1486-94

[84] Voelker J, Berg PH, Sheetz M, Duffin K, Shen T, Moser B, et al. Anti-TGF-beta1 antibody therapy in patients with diabetic nephropathy. J Am Soc Nephrol 2017; 28:953-62.

[85] Wahab NA, Yevdokimova N, Weston BS, Roberts T, Li XJ, 
Brinkman $\mathrm{H}$, et al. Role of connective tissue growth factor in the pathogenesis of diabetic nephropathy. Biochem J 2001; 359:77-87. [86] Adler SG, Schwartz S, Williams ME, Arauz-Pacheco C, Bolton WK, Lee T, et al. Phase 1 study of anti-CTGF monoclonal antibody in patients with diabetes and microalbuminuria. Clin J Am Soc Nephrol 2010; 5:1420-8.

[87] Hunt KJ, Jaffa MA, Garrett SM, Luttrell DK, Lipson KE, LopesVirella MF, et al. Levels of connective tissue growth factor (CTGF) predict development of kidney dysfunction in type 2 diabetes-the VADT study. Diabetes 2018; 67:528-P.

[88] Hong YA, Kim JE, Jo M, Ko GJ. The role of sirtuins in kidney diseases. Int J Mol Sci 2020; 21, 6686.

[89] Anson RM, Guo Z, de Cabo R, Iyun T, Rios M, Hagepanos A, et al. Intermittent fasting dissociates beneficial effects of dietary restriction on glucose metabolism and neuronal resistance to injury from calorie intake. Proc Natl Acad Sci U S A 2003; 100:6216-20. [90] Svendsen PF, Jensen FK, Holst JJ, Haugaard SB, Nilas L, Madsbad S. The effect of a very low calorie diet on insulin sensitivity, beta cell function, insulin clearance, incretin hormone secretion, androgen levels and body composition in obese young women. Scand J Clin Lab Invest 2012; 72:410-9.

[91] Tikoo K, Tripathi DN, Kabra DG, Sharma V, Gaikwad AB Intermittent fasting prevents the progression of type I diabetic nephropathy in rats and changes the expression of sir2 and p53. FEBS Lett 2007; 581:1071-8.

[92] Kitada M, Takeda A, Nagai T, Ito H, Kanasaki K, Koya D. Dietary restriction ameliorates diabetic nephropathy through anti-inflammatory effects and regulation of the autophagy via restoration of SIRT1 in diabetic Wistar fatty (fa/fa) rats: A model of type 2 diabetes. Exp Diabetes Res 2011; 2011:908185.

[93] Baur JA, Pearson KJ, Price NL, Jamieson HA, Lerin C, Kalra $\mathrm{A}$, et al. Resveratrol improves health and survival of mice on a high-calorie diet. Nature 2006; 444:337-42.

[94] Lagouge M, Argmann C, Gerhart-Hines Z, Meziane H, Lerin C, Daussin $\mathrm{F}$, et al. Resveratrol improves mitochondrial function and protects against metabolic disease by activating SIRT1 and PGC1alpha. Cell 2006; 127:1109-22.

[95] Pfluger PT, Herranz D, Velasco-Miguel S, Serrano M, Tschop $\mathrm{MH}$. SIRT1 protects against high-fat diet-induced metabolic damage. Proc Natl Acad Sci U S A 2008; 105:9793-8.

[96] Motonishi S, Nangaku M, Wada T, Ishimoto Y, Ohse T, Matsusaka $\mathrm{T}$, et al. Sirtuin 1 maintains actin cytoskeleton by deacetylation of cortactin in injured podocytes. J Am Soc Nephrol 2015; 26:1939-59.

[97] Nakatani $Y$, Inagi R. Epigenetic regulation through SIRT1 in podocytes. Curr Hypertens Rev 2016; 12:89-94.

[98] Carlomosti F, D’Agostino M, Beji S, Torcinaro A, Rizzi R, Zaccagnini $\mathrm{G}$, et al. Oxidative stress-induced mir-200c disrupts the regulatory loop among SIRT1, FOXO1, and eNOS. Antioxid Redox Signal 2017; 27:328-44.

[99] Xu X, Zheng N, Chen Z, Huang W, Liang T, Kuang H. Puerarin, isolated from Pueraria lobata (Willd.), protects against diabetic nephropathy by attenuating oxidative stress. Gene 2016; 591:411-6.

[100] Wu L, Zhang Y, Ma X, Zhang N, Qin G. The effect of resveratrol on foxo1 expression in kidneys of diabetic nephropathy rats. Mol Biol Rep 2012; 39:9085-93.

[101] Sengupta A, Molkentin JD, Yutzey KE. FoxO transcription factors promote autophagy in cardiomyocytes. J Biol Chem 2009;
284:28319-31

[102] Hariharan N, Maejima Y, Nakae J, Paik J, Depinho RA Sadoshima J. Deacetylation of FoxO by SIRT1 plays an essential role in mediating starvation-induced autophagy in cardiac myocytes. Circ Res 2010; 107:1470-82.

[103] Kume S, Uzu T, Horiike K, Chin-Kanasaki M, Isshiki K, Araki S, et al. Calorie restriction enhances cell adaptation to hypoxia through SIRT1-dependent mitochondrial autophagy in mouse aged kidney. J Clin Invest 2010; 120:1043-55.

[104] Hasegawa K, Wakino S, Simic P, Sakamaki Y, Minakuchi H, Fujimura K, et al. Renal tubular SIRT1 attenuates diabetic albuminuria by epigenetically suppressing claudin-1 overexpression in podocytes. Nat Med 2013; 19:1496-504.

[105] Hasegawa K, Wakino S, Sakamaki Y, Muraoka H, Umino $\mathrm{H}$, Minakuchi $\mathrm{H}$, et al. Communication from tubular epithelial cells to podocytes through SIRT1 and nicotinic acid metabolism. Curr Hypertens Rev 2016; 12:95-104.

[106] Gasparini C, Feldmann M. Nf-kappaB as a target for modulating inflammatory responses. Curr Pharm Des 2012; 18:5735-45.

[107] Du YG, Zhang KN, Gao ZL, Dai F, Wu XX, Chai KF. Tangshen formula improves inflammation in renal tissue of diabetic nephropathy through SIRT1/Nf-kappaB pathway. Exp Ther Med 2018; 15 : 2156-64.

[108] Guo R, Liu B, Wang K, Zhou S, Li W, Xu Y. Resveratrol ameliorates diabetic vascular inflammation and macrophage infiltration in $\mathrm{db} / \mathrm{db}$ mice by inhibiting the Nf-kappaB pathway. Diab Vasc Dis Res 2014; 11:92-102

[109] Liu R, Zhong Y, Li X, Chen H, Jim B, Zhou MM, et al. Role of transcription factor acetylation in diabetic kidney disease. Diabetes 2014; 63:2440-53

[110] Jha JC, Gray SP, Barit D, Okabe J, El-Osta A, Namikoshi T, et al. Genetic targeting or pharmacologic inhibition of NADPH oxidase NOX4 provides renoprotection in long-term diabetic nephropathy. J Am Soc Nephrol 2014; 25:1237-54.

[111] Jha JC, Thallas-Bonke V, Banal C, Gray SP, Chow BS, Ramm $\mathrm{G}$, et al. Podocyte-specific nox4 deletion affords renoprotection in a mouse model of diabetic nephropathy. Diabetologia 2016; 59:379-89. [112] Ong ALC, Ramasamy TS. Role of SIRTUIN1-p53 regulatory axis in aging, cancer and cellular reprogramming. Ageing Res Rev 2018; 43:64-80.

[113] Wang XL, Wu LY, Zhao L, Sun LN, Liu HY, Liu G, et al. SIRT1 activator ameliorates the renal tubular injury induced by hyperglycemia in vivo and in vitro via inhibiting apoptosis. Biomed Pharmacother 2016; 83:41-50.

[114] Tikoo K, Singh K, Kabra D, Sharma V, Gaikwad A. Change in histone h3 phosphorylation, MAP kinase p38, SIR 2 and p53 expression by resveratrol in preventing streptozotocin induced type I diabetic nephropathy. Free Radic Res 2008; 42:397-404.

[115] Wang Y, Zheng ZJ, Jia YJ, Yang YL, Xue YM. Role of p53/miR$155-5 \mathrm{p} / \mathrm{sirt} 1$ loop in renal tubular injury of diabetic kidney disease. J Transl Med 2018; 16:146.

[116] Wen D, Huang X, Zhang M, Zhang L, Chen J, Gu Y, et al. Resveratrol attenuates diabetic nephropathy via modulating angiogenesis. PLoS One 2013; 8:e82336.

[117] Shao Y, Lv C, Wu C, Zhou Y, Wang Q. Mir-217 promotes inflammation and fibrosis in high glucose cultured rat glomerular mesangial cells via Sirt1/HIF-1alpha signaling pathway. Diabetes Metab Res 
Rev 2016; 32:534-43.

[118] Takiyama Y, Haneda M. Hypoxia in diabetic kidneys. Biomed Res Int 2014; 2014:837421.

[119] Ruderman NB, Xu XJ, Nelson L, Cacicedo JM, Saha AK, Lan F, et al. AMPK and SIRT1: A long-standing partnership? Am J Physiol Endocrinol Metab 2010; 298:E751-60.

[120] Kume S, Kitada M, Kanasaki K, Maegawa H, Koya D. Antiaging molecule, SIRT1: A novel therapeutic target for diabetic nephropathy. Arch Pharm Res 2013; 36:230-6.

[121] Kume S, Koya D, Uzu T, Maegawa H. Role of nutrient-sensing signals in the pathogenesis of diabetic nephropathy. Biomed Res Int 2014; 2014:315494

[122] Lan F, Cacicedo JM, Ruderman N, Ido Y. SIRT1 modulation of the acetylation status, cytosolic localization, and activity of LKB1. Possible role in amp-activated protein kinase activation. J Biol Chem 2008; 283:27628-35.

[123] Fulco M, Cen Y, Zhao P, Hoffman EP, McBurney MW, Sauve $\mathrm{AA}$, et al. Glucose restriction inhibits skeletal myoblast differentiation by activating SIRT1 through AMPK-mediated regulation of NAMPT. Dev Cell 2008; 14:661-73.

[124] Kitada M, Ogura Y, Monno I, Koya D. Regulating autophagy as a therapeutic target for diabetic nephropathy. Curr Diab Rep 2017; 17:53.

[125] Ma L, Fu R, Duan Z, Lu J, Gao J, Tian L, et al. SIRT1 is essential for resveratrol enhancement of hypoxia-induced autophagy in the type 2 diabetic nephropathy rat. Pathol Res Pract 2016; 212:310-8. [126] Tang F, Hao Y, Zhang X, Qin J. Effect of echinacoside on kidney fibrosis by inhibition of TGF-beta1/Smads signaling pathway in the $\mathrm{db} / \mathrm{db}$ mice model of diabetic nephropathy. Drug Des Devel Ther 2017; 11:2813-26.

[127] Yao Y, Li Y, Zeng X, Ye Z, Li X, Zhang L. Losartan alleviates renal fibrosis and inhibits endothelial-to-mesenchymal transition (EMT) under high-fat diet-induced hyperglycemia. Front Pharmacol 2018; 9:1213.

[128] Bugyei-Twum A, Ford C, Civitarese R, Seegobin J, Advani SL, Desjardins JF, et al. Sirtuin 1 activation attenuates cardiac fibrosis in a rodent pressure overload model by modifying Smad2/3 transactivation. Cardiovasc Res 2018; 114:1629-41.

[129] Li J, Qu X, Ricardo SD, Bertram JF, Nikolic-Paterson DJ. Resveratrol inhibits renal fibrosis in the obstructed kidney: Potential role in deacetylation of Smad3. Am J Pathol 2010; 177:1065-71.

[130] Jiao X, Li Y, Zhang T, Liu M, Chi Y. Role of sirtuin3 in high glucose-induced apoptosis in renal tubular epithelial cells. Biochem Biophys Res Commun 2016; 480:387-93.

[131] Wang XX, Edelstein MH, Gafter U, Qiu L, Luo Y, Dobrinskikh E, et al. $\mathrm{G}$ protein-coupled bile acid receptor tgr5 activation inhibits kidney disease in obesity and diabetes. J Am Soc Nephrol 2016; 27:1362-78. [132] Srivastava SP, Li J, Kitada M, Fujita H, Yamada Y, Goodwin $\mathrm{JE}$, et al. Sirt3 deficiency leads to induction of abnormal glycolysis in diabetic kidney with fibrosis. Cell Death Dis 2018; 9:997.

[133] Shi JX, Wang QJ, Li H, Huang Q. Sirt4 overexpression protects against diabetic nephropathy by inhibiting podocyte apoptosis. Exp Ther Med 2017; 13:342-8.

[134] Liu M, Liang K, Zhen J, Zhou M, Wang X, Wang Z, et al. Sirt6 deficiency exacerbates podocyte injury and proteinuria through targeting notch signaling. Nat Commun 2017; 8:413.

[135] Ji L, Chen Y, Wang H, Zhang W, He L, Wu J, et al. Overexpression of Sirt6 promotes M2 macrophage transformation, alleviating renal injury in diabetic nephropathy. Int J Oncol 2019; 55:103-15.

[136] Hebert AS, Dittenhafer-Reed KE, Yu W, Bailey DJ, Selen ES, Boersma MD, et al. Calorie restriction and Sirt3 trigger global reprogramming of the mitochondrial protein acetylome. Mol Cell 2013; 49:186-99. [137] Rardin MJ, He W, Nishida Y, Newman JC, Carrico C, Danielson $\mathrm{SR}$, et al. Sirt5 regulates the mitochondrial lysine succinylome and metabolic networks. Cell Metab 2013; 18:920-33.

[138] Buler M, Andersson U, Hakkola J. Who watches the watchmen? Regulation of the expression and activity of sirtuins. FASEB J 2016; 30:3942-60.

[139] Magni M, Buscemi G, Maita L, Peng L, Chan SY, Montecucco A, et al. TSPYL2 is a novel regulator of SIRT1 and p300 activity in response to DNA damage. Cell Death Differ 2019; 26:918-31.

[140] Chai Z, Sarcevic B, Mawson A, Toh BH. Set-related cell division autoantigen-1 (CDA1) arrests cell growth. J Biol Chem 2001; 276:33665-74.

[141] Delbridge ML, Longepied G, Depetris D, Mattei MG, Disteche CM, Marshall Graves JA, et al. TSPY, the candidate gonadoblastoma gene on the human y chromosome, has a widely expressed homologue on the $\mathrm{X}$ - Implications for $\mathrm{Y}$ chromosome evolution. Chromosome Res 2004; 12:345-56.

[142] Eichmuller S, Usener D, Thiel D, Schadendorf D. Tumorspecific antigens in cutaneous T-cell lymphoma: Expression and sero-reactivity. Int J Cancer 2003; 104:482-7.

[143] Sun G, Yuen Chan S, Yuan Y, Wang Chan K, Qiu G, Sun K, et al. Isolation of differentially expressed genes in human heart tissues. Biochim Biophys Acta 2002; 1588:241-6.

[144] Ozbun LL, You L, Kiang S, Angdisen J, Martinez A, Jakowlew SB. Identification of differentially expressed nucleolar TGF-beta1 target (DENTT) in human lung cancer cells that is a new member of the TSPY/SET/NAP-1 superfamily. Genomics 2001; 73:179-93.

[145] Wang GS, Hong CJ, Yen TY, Huang HY, Ou Y, Huang TN, et al. Transcriptional modification by a CASK-interacting nucleosome assembly protein. Neuron 2004; 42:113-28.

[146] Chai Z, Dai A, Tu Y, Li J, Wu T, Wang Y, et al. Genetic deletion of cell division autoantigen 1 retards diabetes-associated renal injury. J Am Soc Nephrol 2013; 24:1782-92.

[147] Tu Y, Wu W, Wu T, Cao Z, Wilkins R, Toh BH, et al. Antiproliferative autoantigen cda1 transcriptionally up-regulates p21(Waf1/Cip1) by activating p53 and MEK/ERK1/2 MAPK pathways. J Biol Chem 2007; 282:11722-31.

[148] Kim TY, Zhong S, Fields CR, Kim JH, Robertson KD. Epigenomic profiling reveals novel and frequent targets of aberrant DNA methylation-mediated silencing in malignant glioma. Cancer Res 2006; 66:7490-501.

[149] Eyler CE, Wu Q, Yan K, Macswords JM, Chandler-Militello $\mathrm{D}$, Misuraca $\mathrm{KL}$, et al. Glioma stem cell proliferation and tumor growth are promoted by nitric oxide synthase-2. Cell 2011; 146:53-66.

[150] Chai Z, Wu T, Dai A, Huynh P, Koentgen F, Krippner G, et al. Targeting the cda1/cda1bp1 axis retards renal fibrosis in experimental diabetic nephropathy. Diabetes 2019; 68:395-408. 